\title{
Evaluation of Rise in Pulp Chamber Temperature after Activation with Different Curing Lights on Bleached Teeth-An In Vitro Study
}

\author{
Aditya Bansal ${ }^{1}$ Yogesh Kumar ${ }^{1} \quad$ Neetu Jindal ${ }^{1} \quad$ Renu Aggarwal $^{1}$ Somya Jain ${ }^{1}$ \\ ${ }^{1}$ Department of Conservative Dentistry and Endodontics, \\ Surendera Dental College and Research Institute, Sri Ganganagar, \\ Rajasthan, India

\begin{abstract}
Address for correspondence Neetu Jindal, MDS, Department of Conservative Dentistry and Endodontics, Surendera Dental College and Research Institute, H.H Gardens, Sadul Shahar Road, Sri Ganganagar 335001, Rajasthan, India
\end{abstract} \\ (e-mail: drneetujindal@gmail.com).
}

Dent J Adv Stud:2020;8:80-83

\begin{abstract}
Introduction The aim of the study was to evaluate rise in pulp chamber temperature after activation with different curing lights on bleached teeth in an in vitro study. The present study is an in vitro study with a sample size of 100 . A total of 100 human extracted maxillary central and lateral incisors were collected and then randomly assigned into one control group and four experimental groups $(n=20)$.

Material and Methods As many as 100 freshly extracted noncarious human maxillary central and lateral incisor teeth were used in this study. The access opening of all 100 samples were done to facilitate access to the pulp chambers for measuring the temperature. The samples were embedded into the additional silicone model, and uniform distance of $5 \mathrm{~mm}$ from tooth surface was taken for gel activation using different curing lights (LED, QTH, plasma arc, diode laser). The temperature inside the pulp chamber was measured using digital infrared thermometer. Infrared light of infrared thermometer was put on pulp chamber before the bleaching gel application $\left(T_{0}\right) 1$ minute after bleaching gel application $\left(\mathrm{T}_{1}\right)$. Later, there was changing of color of bleaching gel from dark red into green color when activated with different curing lights (T2).

Statistical Analysis The temperature data obtained were analyzed statistically by one-way ANOVA and posthoc Tukey's tests. Significance level was set at 5\% for all analyses.

Results The mean and standard deviation (SD) values of rise in pulp chamber temperature after activation with different light sources were Group II (LED) $0.5 \pm 0.466$,

Keywords

- light activated

bleaching

- pulp chamber

temperature

Group III (QTH) $0.775 \pm 0.229$, Group IV (plasma arc) $1.26 \pm 0.690$, and Group V (diode laser) $1.355 \pm 0.452$.

Conclusion Compared with other light-curing units, LED group induced lowest rise in pulp chamber temperature. Whereas, bleaching without light activation does not induce rise in pulp chamber temperature.
\end{abstract}

\section{Introduction}

Aesthetics, by definition, is the science of beauty, or the particular detail of an animate or inanimate object that makes it appealing to the eye. ${ }^{1}$ The rising cultural demand of beauty has reached high proportions. Great appearance has a significant role in personal and professional achievement. ${ }^{2}$
Bleaching has been used as a corrective measure for treatment of discolored teeth. It can be done internally on nonvital teeth or externally on vital teeth. ${ }^{1}$ Bleaching procedure can be performed at office, home, or a combination of both. A high-concentration (15-38\%) is usually used for bleaching procedures. ${ }^{3}$ 
Various external sources can be used to fasten the chemical decomposition of bleaching agent and achieving whiter smile in a short period of time. However, there is a greater concern regarding heat generation by these light sources, with the danger of pulp necrosis. Light activation unit that generates high-energy can induce significant rise in intrapulpal temperature compared with bleaching without light activation. ${ }^{4}$

Factors which may affect the rise in pulpal temperature are thickness of dentin, time duration of light exposure, and type of light activation source. ${ }^{5}$ Thus, the purpose of this study was to evaluate rise in pulp chamber temperature after activation with different curing lights on bleached teeth.

\section{Objective}

The objective of this study was to evaluate the rise in pulp chamber temperature after activation with different curing lights on bleached teeth in an in vitro study.

\section{Materials and Methods}

A total of 100 freshly extracted noncarious human maxillary central and lateral incisor teeth were used in this study. Soft-tissue and calculus were removed mechanically from tooth surfaces. The prophylaxis of the tooth crown was performed using rubber cup with pumice. The access opening of all 100 samples were done with No. 2 round bur (Dentsply) to facilitate access to the pulp chambers for measuring the temperature. The specimens were stored in saline at room temperature for 24 hours. The dental structure thickness was measured from labial surface to inner wall of pulp chamber with the help of a crown gauge. The thickness of all samples should be a uniform $2.5 \mathrm{~mm}$. The samples were embedded into the additional silicone model, and a uniform distance of $5 \mathrm{~mm}$ from tooth surface was taken for gel activation using different curing lights.

The selected 100 samples were then randomly assigned into one control group and four experimental groups $(n=20)$.

- Group I control group (no light activation).

- Group II LED (Woodpecker, China) (650 MW/ $\mathrm{cm}^{2}$, $420-480 \mathrm{~nm})$.

- Group III QTH (QHL 75, China) (450 MW/ $\mathrm{cm}^{2}$, 400-500 nm).

- Group IV plasma arc (Monitex SP 2000, Taiwan) (1800 MW/ $\left./ \mathrm{cm}^{2}, 430-470 \mathrm{~nm}\right)$.

- Group V diode laser (FONA Laser, Italy) (3 W, $970 \mathrm{~nm}$ ).

After access opening, the bleaching gel 35\% hydrogen peroxide (Whiteness HP; FGM, Joinville, SC, Brazil) was applied over the entire labial surface of samples, forming a 0.5 to $1.0 \mathrm{~mm}$-thick layer and allowing the bleaching agent to remain undisturbed for 1 minute ( $\mathbf{- F i g}$. 1A). After that, light activation was done using different curing lights (control group, light emitting diode, quartz tungsten halogen, plasma arc, diode laser), keeping a distance of $5 \mathrm{~mm}$ from the gel surface. The temperature inside the pulp chamber
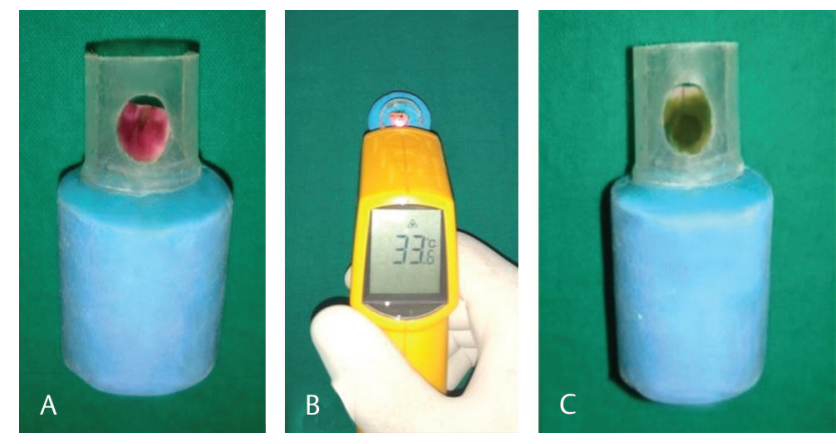

Fig. 1 (A) Bleaching agent applied over the labial surface of the tooth. (B) Temperature recorded with infrared thermometer. (C) Bleaching color changes after light activation from red to dark green.

was measured using digital infrared thermometer (FLUKE 59 Mini, China) (-Fig. 1B). Infrared light of infrared thermometer was put on pulp chamber before the bleaching gel application $\left(\mathrm{T}_{0}\right) 1$ minute after bleaching gel application $\left(\mathrm{T}_{1}\right)$, Later, there was changing of color of bleaching gel from dark red into green color when activated with different curing lights (T2) (-Fig. 1C). In case of control group, no light activation was done, and temperature recorded when bleaching gel color changes from dark red into green color.

\section{Statistical Analysis}

The temperature data obtained were analyzed statistically by one-way ANOVA and posthoc Tukey's tests. Significance level was set at $5 \%$ for all analyses.

\section{Results}

The mean and standard deviation (SD) values of rise in pulp chamber temperature after application of bleaching gel without activation and with different curing units were Group I (control group) $-0.09 \pm 0.165$, Group II (LED) $-0.245 \pm 0.287$, Group III (QTH) $-0.17 \pm 0.134$, Group IV (plasma arc) $-0.18 \pm$ 0.330 , and Group V (diode laser) $-0.12 \pm 0.177$.

On the basis of above observation and their analysis, the rise in pulp chamber temperature after application of bleaching gel was not significant $(p>05)$.

The mean and SD values of rise in pulp chamber temperature after activation with different light sources were Group II (LED) $0.5 \pm 0.466$, Group III (QTH) $0.775 \pm 0.229$, Group IV (plasma arc) $1.26 \pm 0.690$, and Group V (diode laser) $1.355 \pm 0.452$ (- Table 1).

The order of rise in pulp chamber temperature after activation with different curing lights on bleached teeth was as follows:

\section{Group II< Group III $<$ Group IV $<$ Group V}

The intergroup comparison shows that Group II (LED) had shown lowest rise in pulp chamber temperature as compared with Group III (QTH), Group IV (plasma arc) and Group V (diode laser), and it showed nonsignificant $p$ value 
Table 1 Demonstrates the intragroup mean and SD values of rise in pulp chamber temperature after activation with different curing lights on bleached teeth by using one-way ANOVA

\begin{tabular}{|c|c|c|c|c|c|}
\hline Groups & Mean & SD & F value & $p$-Value & Status \\
\hline Group II (LED) & 0.5 & 0.466 & \multirow{4}{*}{13.79} & \multirow{4}{*}{$<0.001$} & \multirow{4}{*}{ Highly significant } \\
\hline Group III(QTH) & 0.775 & 0.229 & & & \\
\hline Group IV (plasma arc) & 1.26 & 0.690 & & & \\
\hline Group V (diode laser) & 1.355 & 0.452 & & & \\
\hline
\end{tabular}

Abbreviation: SD, standard deviation.

Note: $p$-Value $<0.01$ highly significant.

Table 2 Demonstrates the pair wise intergroup comparison of mean values of rise in pulp chamber temperature after activation with different curing lights on bleached teeth using posthoc Tukey's HSD test

\begin{tabular}{|l|l|l|l|l|}
\hline Intergroup comparison & $\begin{array}{l}\text { Mean diff. } \\
\text { (T2-T1) }\end{array}$ & Q value & $p$-Value & Status \\
\hline $\begin{array}{l}\text { Group (II vs. III) } \\
\text { LED vs. QTH }\end{array}$ & 1.02 & 2.523 & 0.289 & NS \\
\hline $\begin{array}{l}\text { Group (II vs. IV) } \\
\text { LED vs. plasma arc }\end{array}$ & 0.68 & 6.973 & 0.001 & SIG \\
\hline $\begin{array}{l}\text { Group (II vs. V) } \\
\text { LED vs. diode laser }\end{array}$ & 1.6 & 7.845 & 0.001 & SIG \\
\hline $\begin{array}{l}\text { Group (III vs. IV) } \\
\text { QTH vs. plasma arc }\end{array}$ & 0.955 & 4.450 & 0.012 & SIG \\
\hline $\begin{array}{l}\text { Group (III vs. V) } \\
\text { QTH vs. diode laser }\end{array}$ & 0.58 & 5.322 & 0.002 & SIG \\
\hline $\begin{array}{l}\text { Group (IV vs. V) } \\
\text { Plasma arc vs. diode laser }\end{array}$ & 1.535 & 0.872 & 0.900 & NS \\
\hline
\end{tabular}

Abbreviation: HSD, honest significance difference.

Note: $p$-Value $<0.001$ highly significant.

$p$-Value $>0.05$ nonsignificant.

with Group III $(\mathrm{p}>0.05)$ but significant $p$ value came with Group IV and V ( $p=0.001)$. Group V (diode laser) revealed highest rise in pulp chamber temperature as compared with Group II (LED), Group III (QTH), and Group IV (plasma arc), and it showed nonsignificant $p$ value with Group IV $(p>0.05)$ and significant values with Group III $(p<0.05)$ and Group II $(p=0.001)(-$ Table 2$)$.

\section{Discussion}

It is well-known that light activation increases the effectiveness of bleaching procedure. However, this may cause thermal damage to pulp tissue. ${ }^{6}$ This present study aims to compare the effect of different light sources on rise in intrapulpal temperature.

In the present study, the use of diode laser with $3 \mathrm{~W}$ power output showed highest rise in intrapulpal temperature as compared with LED, halogen and plasma arc. This finding is in accordance with other similar type of studies where highest rise in intrapulpal temperature was found with diode laser during bleaching procedure. Kivanc et al found that $3 \mathrm{~W}$ diode laser exhibited the highest rise in intrapulpal temperature because of high-energy output. The intrapulpal temperature increase with increase in energy output and wavelength and diminished with greater dentin thickness. ${ }^{7}$

Eldeniz et al found that the diode laser $(10 \mathrm{~W})$ exhibited highest rise, and LED $\left(380 \mathrm{MW} / \mathrm{cm}^{2}\right)$ showed least rise in pulp chamber temperature because of high-energy output, which significantly increased pulp chamber temperature during tooth bleaching. ${ }^{1}$

Zach and Cohen reported that temperature elevation exceeding $16.6^{\circ} \mathrm{C}$ would have caused irreversible pulpal damage in almost $100 \%$ of teeth. The study showed potential histopathological changes in the pulp tissue when temperature rise exceeded $5.5^{\circ} \mathrm{C}$. But in the present study, none of the groups showed rise in intrapulpal temperature exceeding $5.5^{\circ} \mathrm{C} .{ }^{8}$

In addition, there was no significant difference between values of LED and QTH and plasma arc and diode laser. However, this result is not in accordance with those of Ulusoy et $\mathrm{a}^{9}$ and Carrasco et al ${ }^{10}$ who reported highest rise in intrapulpal temperature with halogen compared with LED.

The thermal pulp damage and severity of pulp response depends on duration and power output of activation sources. Kreisler et al suggested a dentin thickness of $2 \mathrm{~mm}$ for safe irradiation and stated that thickness of dentin have a protective effect against pulp heating. ${ }^{11}$ 
The applied bleaching gel may act as an insulator which can reduce the rise in intrapulpal temperature as compared with bleaching without light activation. The inorganic load in bleaching agent acts as a barrier and collector of heat waves, which allows heat wave to be used in the gel and avoid directly heating the pulp. ${ }^{12}$

There is a limited data available indicating the effect of light activation on the overall health of pulp. Although elevation of pulp temperature during light activated bleaching may be detrimental to pulp tissue, the pulp may still survive this aseptic injury via tissue regeneration.

In addition, other factors like local blood flow, dentinal fluid flow, and surrounding tissue may impede the transfer of heat to the pulp. Yet, the deleterious effect of laser system on pulpal health should be weighed against merits of laser use in bleaching procedures. ${ }^{13}$

\section{Conclusion}

All activation groups showed statistically significant rise in pulp chamber temperature but the maximum temperature remained below the critical level of $5.5^{\circ} \mathrm{C}$. Rather, bleaching agent functioned as a protective barrier against the intrapulpal temperature increase. The control group did not show rise in pulp chamber temperature when no light activation was done.

Intensity and characteristics of curing lights played an important role in temperature increase. Infrared digital thermometer is a viable means of quantifying the change in temperature during tooth bleaching with light curing units. Higher power intensity curing lights should be used for shorter period of time to avoid undesired pulpal response.

\section{Conflict of Interest}

None declared.

\section{References}

1 Eldeniz AU, Usumez A, Usumez S, Ozturk N. Pulpal temperature rise during light-activated bleaching. J Biomed Mater Res B Appl Biomater 2005;72(2):254-259

2 Michida SMDA, Passos SP, Marimoto ARK, Garakis MCV, de Araújo MA. Intrapulpal temperature variation during bleaching with various activation mechanisms. J Appl Oral Sci 2009;17(5):436-439

3 Mondelli RFL, Soares AF, Pangrazio EGK, Wang L, Ishikiriama SK, Bombonatti JF. Evaluation of temperature increase during in-office bleaching. J Appl Oral Sci 2016;24(2):136-141

4 Hahn P, Schondelmaier N, Wolkewitz M, Altenburger MJ, Polydorou O. Efficacy of tooth bleaching with and without light activation and its effect on the pulp temperature: an in vitro study. Odontology 2013;101(1):67-74

5 Park SH, Roulet JF, Heintze SD. Parameters influencing increase in pulp chamber temperature with light-curing devices: curing lights and pulpal flow rates. Oper Dent 2010;35(3):353-361

6 Hein DK, Ploeger BJ, Hartup JK, Wagstaff RS, Palmer TM, Hansen LD. In-office vital tooth bleaching-what do lights add? Compend Contin Educ Dent 2003;24(4A):340-352

7 Kivanç BH, Arisu HD, Ulusoy OIA, Sağlam BC, Görgül G. Effect of light-activated bleaching on pulp chamber temperature rise: an in vitro study. Aust Endod J 2012;38(2):76-79

8 Zach L, Cohen G. Pulp response to externally applied heat. Oral Surg Oral Med Oral Pathol 1965;19:515-530

9 Ulusoy C, Irmak O, Bagis YH, Ulusoy OI. Temperature rise and shear bond strength of bondable buccal tubes bonded by various light sources. Eur J Orthod 2008;30(4):413-417

10 Carrasco TG, Carrasco-Guerisoli LD, Fröner IC. In vitro study of the pulp chamber temperature rise during light-activated bleaching. J Appl Oral Sci 2008;16(5):355-359

11 Kreisler M, Al-Haj H, D'Hoedt B. Intrapulpal temperature changes during root surface irradiation with an 809-nm GaAlAs laser. Oral Surg Oral Med Oral Pathol Oral Radiol Endod 2002;93(6):730-735

12 Loney RW, Price RB. Temperature transmission of highoutput light-curing units through dentin. Oper Dent 2001; 26(5):516-520

13 Raab WH. Temperature related changes in pulpal microcirculation. Proc Finn Dent Soc 1992;88(Suppl 1):469-479 